* Pós-Doutor em Direito em 2019 pela Universidade de Fortaleza (UNIFOR)

Doutor em Direito Constitucional nas Relações Privadas em 2015 pela Universidade de Fortaleza (UNIFOR)

Mestre em Direito Constitucional nas Relações Privadas em 2012 pela Universidade de Fortaleza (UNIFOR)

Especialista em Direito do Trabalho, Tributário e Previdenciário em 2010 pela Faculdade Ateneu (FATE)

Graduado em Direito em 2009 pela Universidade de Fortaleza (UNIFOR)

\section{CONTRATUALISMO X INSTITUCIONALISMO: A BUSCA POR UM CAMINHO PARA A CIÊNCIA DO DIREITO DO TRABALHO}

\author{
CONTRATUALISM X INSTITUTIONALISM: THE \\ SEARCH FOR A WAY FOR THE SCIENCE OF LABOR \\ LAW
}

\section{Saulo Nunes de Carvalho Almeida*}

Como citar: ALMEIDA, Saulo Nunes de Carvalho. Contratualismo x institucionalismo: a busca por um caminho para a ciência do direito do trabalho. WTO-OSC/ds267 - Pland Cotton. Scientia Iuris, Londrina, v. 23, n. 2, p. 166-182, jul. 2019. DOI: $10.5433 / 2178-8189.2019 v 23 n 2 p 166$. ISSN: 21788189.

Resumo: O Direito do Trabalho brasileiro encontra-se em uma encruzilhada. A Lei $\mathrm{n}^{\circ}$ 13.467/2017 ("Reforma Trabalhista"), que justificou o desenvolvimento desse estudo, não apenas alterou um vasto plexo de direitos e garantias trabalhistas. A mesma norma reacendeu, como nunca, o debate acerca de um direito trabalhista mais flexível, com maior espaço para autonomia contratual e uma proporcional retirada do modelo de intervencionismo estatal, correspondendo, esse embate, ao objeto de estudo desenvolvido. Para o presente ensaio, o procedimento metodológico empregado foi eminentemente descritivo e exploratório, norteado por uma pesquisa qualitativa, composta pela análise de fontes bibliográficas e documentais. No quesito problematização, o enfoque correspondeu a necessária análise do atual contexto experimentado pelo Direito do Trabalho pátrio, em que juslaboralistas tem argumentado que esse ramo científico está se afastando de seus pressupostos constitucionais de valorização do trabalho humano e promoção da justiça social, especialmente após a vigência da Lei $\mathrm{n}^{\circ} 13.467 / 2017$. Por fim, concluiu-se que a substituição do modelo juslaboral intervencionista por uma modelo eminentemente contratualista, considerando o contexto experimentado pelo sindicalismo brasileiro, poderá resultar na mitigação de direitos trabalhistas fundamentais.

PALAVRAS-CHAVES: Direito do Trabalho Contratual; Limites do Intervencionismo; Futuro do Direito do Trabalho. 
Abstract: Brazilian Labor Law is at a crossroads. Law 13,467 / 2017 ("Labor Reform"), which justified the development of this study, has not only altered a broad range of labor rights and guarantees. The same norm rekindled, as never before, the debate about a more flexible labor law, with more room for contractual autonomy and a proportional withdrawal from the model of state interventionism. For the present essay, the methodological procedure used was eminently descriptive and exploratory, guided by a qualitative research, composed by the analysis of bibliographic and documentary sources. In the question of problematization, the focus will be the necessary analysis of the current context experienced by the Labor Law, where juslaboralists have argued that this branch of science is moving away from its constitutional presuppositions of valuing human work and promoting social justice, especially after validity of Law n ${ }^{\circ} 13467 / 2017$. Finally, it was concluded that the substitution of the interventionist labor model by an eminently contractualist model, considering the context experienced by Brazilian trade unionism, could result in the mitigation of fundamental labor rights.

Keywords: Contract Labor Law; Limits of Interventionism; Future of Labor Law. 


\section{INTRODUÇÃO}

Em face da atual crise do ramo científico intitulado Direito do Trabalho, bem como a emergência de doutrinas defensoras da construção de um novo modelo socioeconômico, pautado em feições humanistas e solidárias, presencia-se um debate crescente acerca da necessária concepção de um sistema justrabalhista mais adequado do que aquele instituído com a vigência da Lei $\mathrm{n}^{\text {o }}$ 13.467/2017 ("Reforma Trabalhista"), capaz de melhor enfrentar distintas e complexas questões humanas da contemporaneidade.

Como se sabe, a reforma trabalhista fortaleceu o direcionamento do Direito do Trabalho brasileiro rumo a um modelo dotado de feições eminentemente contratualista, Sob o argumento de reconhecimento da liberdade econômica, foi concedido vasto espaço para acordos e convenções coletivas de trabalho, que agora poderão "flexibilizar" um vasto plexo de direitos que, até então, experimentavam natureza jurídica inalienável, conforme pode ser observado no teor do novo artigo 611-A da CLT.

Manifestando-se de forma antagônica aos valores resultantes dessa normatização, a resposta de significativa maioria dos pesquisadores, juristas e demais intelectuais que integram o juslaboralismo pátrio tem sido o de criticar a sistemática de fortalecimento da sobreposição da negociação sobre a lei, ao mesmo passo em que se argumenta em prol de um modelo com feições mais intervencionista de direito laboral, capaz de assegurar as garantias trabalhistas natureza jurídica de direitos fundamentais inalienáveis.

Nesse contexto, será utilizado como problematização central para o presente ensaio, aquilo que aparenta se tornar um infindável debate: qual seria a melhor alternativa para o sistema jurídico brasileiro, um modelo juslaboral com feições contratualista ou institucionalista?

Seguindo o objetivo principal proposto, qual seja, enfrentar a problematização acerca dos rumos futuros a serem traçados pelo Direito do Trabalho brasileiro, optou-se, para o desenvolvimento desse artigo, pela adoção do procedimento metodológico descritivo e exploratório, desenvolvido por uma pesquisa qualitativa e exemplificativa, composta, em essência, pelo estudo crítico de fontes de pesquisas documentais e bibliográficas.

Por fim, para conferir melhor lógica ao ensaio, adequado esclarecer o trajeto o qual o estudo irá adotar. Como opção teórico-metodológico, a exposição sistemática da matéria ocorrerá na forma de três seções. Na primeira parte, as ideologias de sistemas jurídicos trabalhistas contratualisas e intervencionistas são apresentas e criticamente analisadas. Na segunda seção, a cientificidade do pós-positivismo jurídico é posta sob análise, ao mesmo passo que se examina questões atreladas à difusão do neoconstitucionalismo. No tópico final, é discutido o necessário processo de gradualismo normativo do Direito do Trabalho, o processo de flexibilização normativa experimentada nos últimos governos e seus desafios na contemporaneidade.

\section{ACEPÇÕES INTRODUTÓRIAS DA DICOTOMIA CONTRATUALISTA E INTERVENCIONISTA NO DIREITO DO TRABALHO}


Inicialmente, essa dicotomia doutrinária acerca de modelos contratualistas e intervencionistas, quando estudada à luz de análise minuciosa dos sistemas jurídicos contemporâneos, tem revelado certas inadequações. A realidade é que em um panorama global, hodiernamente o Direito do Trabalho aparenta adotar um modelo que pode ser considerado como "misto", preenchido por fontes produzidas pelo Estado bem como pelos agentes integrantes da relação. Isso significa que, na atualidade, a conceituação de um modelo jurídico como contratual ou negociado é feito por uma análise do grau de normatização existente e do espaço reservado ao preenchimento dos direitos/obrigações pela vontade dos particulares.

Modelos "protecionistas-intervencionistas" ainda preservam certo grau de autonomia privada, bem como modelos "liberalistas-contratualistas" toleram certo grau de normatização estatal. Ao contrário do que tais "rótulos" podem levar a entender, a realidade é que a complexidade das relações socioeconômicas contemporâneas impossibilitam a manutenção de "pureza" em qualquer dos modelos ${ }^{1}$, ou seja, não há qualquer sistema justrabalhista democrático integralmente regido por normas estatais ou contratos privados ${ }^{2}$.

Após esses necessários esclarecimentos acerca da imprecisão presente nessa dicotomia, retoma-se a questão central.

O debate ora proposto, e suas tensões, é inspirado na busca pelo melhor caminho para a construção de um novo Direito do Trabalho, mais adequado as características presentes no sistema de Estado e econômico da contemporaneidade:

De modo singelo, o contratualismo é o regime de relações de trabalho marcado por três elementos: manifestação livre de vontade convergentes, expressão de interesses comuns e consensuais, alto grau de cooperação; já o institucionalismo seria marcado pelo reconhecimento, por um terceiro interessado - o Estado, de símbolos de pertencimento e de destino comum dos membros de uma sociedade, fixando de modo compulsório o conteúdo das relações sociais de produção. (MENDES, 2007, p.50)

Para os defensores do arquétipo contratualista, há uma severa falha no acompanhamento da legislação trabalhista frente à velocidade de rotação do capital globalizado, o que faz com que as fontes jurídicas estatais tendam a atuar como espécie de bloqueio ao aceleramento e desenvolvimento econômico do país:

Argumenta-se que a legislação trabalhista, em especial a CLT, não permite às empresas flexibilizar as condições de trabalho, de forma abrangente e necessária para a sua própria sobrevivência, tendo em vista o atual capitalismo, caracterizado

$1{ }^{1}$ Ao comentar esse dualismo e a visão reducionista daqueles que entendem que a adoção de um modelo (institucionalista ou liberalista) deve significar o abandono de seu "oposto" Tereza Aparecida Asta Gemignani (2010, p.34) relembra que: "Preservando a multiplicidade de enfoques abriu caminho para a construção de alternativas criativas e atreladas à multiplicidade cultural, que se constitui no traço mais característico de nossa nação, não aceitando o beco sem saída e a visão reducionista, que limitam o debate sobre o futuro institucional do Brasil a um singelo braço de ferro entre o socialismo e o liberalismo, por reconhecer que a realidade da vida é muito mais complexa do que esse dualismo."

$2^{2}$ As tendências equivocadas da ciência do direito às dicotomias manifestam-se, até os dias atuais, na clássica divisão entre direito público e direito privado. 
pela acirrada concorrência, cujo alcance chega a superar os limites internos ou nacionais. Nesse enfoque, assevera-se que a rigidez e o protecionismo das normas que disciplinam as relações jurídicas entre empregadores e empregados acabam gerando certo efeito inverno, no sentido de acarretarem dificuldades econômicas às empresas, o que, no entender de certa corrente de pensamento, teria como consequência a cessação de contratos de trabalho, gerando, assim, o desemprego. (GARCIA, 2013, p.51).

Nesse contexto, o contratualismo moderno parte das premissas que a organização social e os princípios básicos a serem seguidos pelos membros de uma sociedade devem ser dirigidos por acordos, contratos celebrados conforme a vontade de indivíduos livres e autônomos ${ }^{3}$. Na sua feição hodierna, defende-se as ideias de flexibilização do trabalho, em oposição a intervenção estatal e o seu "conservadorismo" que mitiga o espectro da negociação, vistos como obstáculos ao desenvolvimento do capitalismo, motivo o qual se defende que empregadores deveriam ter a liberdade plena para organizar o trabalho. Nesse contexto, "poder absoluto dos empregadores sobre o trabalho é disfarçado como flexibilidade do trabalho, significa que trabalhador não tem nenhum direito, o capital possui todos os direitos. O significado operacional de flexibilidade do trabalho é rigidez capitalista ao estabelecer unilateralmente e impor as regras de contratação empregatícia" PETRAS (1996, p. 135).

Nesse cenário emergem fenômenos como os da flexibilização e desregulamentação das relações de trabalho. Medidas apresentadas como a "solução final" que possibilitará a sobrevivência das empresas nacionais frente a dinâmica da realidade econômica global, recaindo sobre o Direito do Trabalho a obrigação de amoldação ou simples extinção": "Em momentos, por exemplo, de dificuldade financeira, reduzir ou mesmo excluir determinados direitos(...). Seria necessário desregulamentar certos aspectos (...) na relação de emprego, prevista na CLT, os quais passariam a ser regidos por normas decorrentes da negociação coletiva de trabalho." GARCIA (2013, p.52).

\section{PERQUIRIÇÕES ACERCA DA CRISE DA LEGALIDADE E O PÓS-POSITIVISMO RELUTANTE}

O pós-positivismo manifesta-se como uma nova forma de compreender a interação entre Direito e sociedade, afastando-se das premissas do direito natural e do direito positivo ${ }^{5}$, emergindo como uma espécie de teoria mista, um híbrido confeccionado pela adoção de concepções oriundas

$3^{3}$ Obviamente, os aspectos acima mencionados correspondem apenas a uma sintetização teórica dos pontos nucleares integrantes das correntes jurídico-econômica ora em estudo. Não significa tratar-se de uma conceituação capaz de rotular políticas públicas ou sistemas jurídicos como contratualistas ou institucionalistas, até porque, na maioria dos casos, essa polarização é inexistente, podendo ser identificado, na realidade, medidas portadoras de ambas as naturezas, porém, em intensidades distintas.

$4{ }^{4}$ Para Ana Virgínia Moreira Gomes (2001, p.98): “O anúncio do 'fim’ do Direito do Trabalho relaciona-se então diretamente com a ideia de que este seria o Direito de um Estado que não mais funciona."

$55^{5}$ Celso Barros (2010, p.162) apresenta síntese simplista, porém, adequada referente a escola do Direito Natural: "Enquanto o Direito Natural tomava conceitos gerais, abstratos para estabelecer as normas disciplinadoras da conduta humana, o Positivismo jurídico colocou-se no extremo oposto e foi encontrar a única explicação do direito na ordem dos fenômenos sociais. O mundo da razão onde se elaboravam os fundamentos do Direito Natural fora substituído pelo mundo da experiência de onde sairia o direito positivo". 
de pensamentos tanto juspositivistas como jusnaturalistas, não havendo uma abrupta ruptura com nenhuma das correntes jusfilosóficas. Aqui, se reconhece o papel da Lei, todavia, atestase, também, a importância de uma observância dos princípios norteadores de uma sociedade democrática. Busca-se, assim, importar componentes e ideologias de ambas escolas, moldando-as em uma estrutura única que alicerçara esse novo sistema jurídico.

Luís Roberto Barroso ${ }^{6}$ (2001, p. 17-19) relembra que o desenvolvimento da cientificidade do positivismo jurídico ocorreu estruturado na ambiciosa atitude de redução do Direito ao conjunto normativo em vigor. Uma fase marcada pelo fetichismo dos juristas à lei, que culminaria com o afastamento do Direito de ideais morais. Para o constitucionalista, essa busca de uma máxima objetividade e neutralidade ${ }^{7}$ da ciência jurídica o distanciou da causa da humanidade:

O positivismo jurídico foi a importação do positivismo filosófico para o mundo do Direito, na pretensão de criar-se uma ciência jurídica, com características análogas as ciências exatas e naturais. A busca de objetividade científica, com ênfase na realidade observável e não na especulação filosófica, apartou o Direito da moral e dos valores transcendentes. Direito é norma, ato emanado do Estado com caráter imperativo e força coativa. (...). O Direito, a partir da segunda metade do século XX, já não cabia mais no positivismo jurídico. A aproximação quase absoluta entre Direito e norma e sua rígida separação da ética não correspondiam ao estágio de processo civilizatório e às ambições dos que patrocinavam a causa da humanidade. (...). Nesse contexto, o pós-positivismo não surge com o ímpeto da desconstrução, mas como uma superação do conhecimento convencional. Ele inicia sua trajetória guardando deferência relativa ao ordenamento positivo, mas nele reintroduzindo as ideias de justiça e legitimidade.

Com a difusão do neoconstitucionalismo ${ }^{8}$, e a passagem da Constituição de uma carta política desvalorizada para o patamar de norma suprema de um ordenamento jurídico, possibilitouse o desenvolvimento de maiores espaços para discussões morais capazes de afetar a hegemonia da lei, evidenciando que a vinculação conceitual entre Direito e valorações morais se encontra presente desde a concepção do Direito, como manifestação dos valores de uma sociedade, motivo pelo qual não deveria ser combatido e sim abraçado.

Ana Paula de Barcellos (2006, p. 32-35) argumenta que esse estado do constitucionalismo contemporâneo reconhecido como neoconstitucionalismo é dotado de alguns elementos particulares que justificam a ascensão da ciência constitucional, podendo ser estudados em dois distintos grupos: os elementos metodológico-formais e os elementos materiais:

$6{ }^{6}$ BARROSO, Luis Roberto. Fundamentos Teóricos e Filosóficos do Novo Direito Constitucional Brasileiro. In Revista Diálogo Jurídico. Ano I. Vol. I. Salvador, set/2001. Disponível em: $<$ http://www.direitopublico.com.br/ pdf 6/dialogo-juridico-06-setembro-2001-luis-roberto-barroso.pdf $>$. Acesso em: 01 ago. 2014.

$7^{7}$ Sobre a visão da ciência do Direito pelo prisma do positivismo jurídico, Noberto Bobbio (1995, p. 135) esclarece: "O positivismo jurídico nasce do esforço de transformar o estudo do direito numa verdadeira e adequada ciência que tivesse as mesmas características físico-matemáticas, naturais e sociais. Ora, a característica fundamental da ciência consiste em sua avaloratividade, isto é, na distinção entre juízos de fato e juízos de valor e na rigorosa exclusão destes últimos do campo científico: a ciência consiste somente em juízos de fato (...). A ciência exclui do próprio âmbito os juízos de valor, porque ela deseja ser um conhecimento puramente objetivo da realidade, enquanto os juízos em questão são sempre subjetivos e consequentemente contrários à exigência da objetividade".

$8{ }^{8}$ De acordo com Max Moller (2011) o neoconstitucionalismo tem como características: rigidez constitucional, garantia jurisdicional da Constituição, força vinculante da Constituição, sobreinterpretação da Constituição, aplicação direta das normas constitucionais, interpretação conforme a lei, influência da Constituição sobre as relações políticas. 
Do ponto de vista metodológico-formal, o constitucionalismo atual opera sobre três premissas fundamentais, das quais depende boa parte a compreensão dos sistemas jurídico-ocidentais contemporâneos. São elas: (i) normatividade da Constituição, isto é, o reconhecimento de que as disposições constitucionais são normas jurídicas, dotadas, como as demais, de imperatividade; (ii) a superioridade da Constituição sobre o restante da ordem jurídica (cuida-se de Constituições rígidas, portanto); e (iii) a centralidade da Carta nos sistemas jurídicos, por força do fato de que os demais ramos do Direito devem ser compreendidos e interpretados a partir do que dispõe a Constituição". (...). Do ponto de vista material, ao menos dois elementos caracterizam o neoconstitucionalismo e merecem nota: (i) a incorporação explícita de valores e opções políticas nos textos constitucionais, sobre tudo no que diz respeito à promoção da dignidade humana e dos direitos fundamentais; (ii) a expansão de conflitos específicos e gerais entre as opções normativas e filosóficas existentes dentro do próprio sistema constitucional.

Essa breve análise evidencia que um dos desafios do positivismo jurídico em sua vertente tradicional repousava no fato de que a norma jurídica não possuía sua carga coativa vinculada ao alcance de determinados standards morais (incontáveis são os exemplos de leis criticadas por apresentarem conteúdo injusto ou imoral $)^{9}$, ou seja, a validade de uma norma jurídica e a sua imperatividade eram características dissociadas de questões referentes à justiça, pois "a circunstância de ser uma norma jurídica justa ou injusta, é uma investigação exclusivamente ética e qualquer que seja a conclusão, continuará ela a ser norma jurídica e, portanto, direito.”COELHO (2008, p. 223).

A moderna dogmática jurídica defende a superação desse cenário presente em teorias reducionistas, reconhecendo que uma coisa é a norma positivada, outra o próprio Direito. A ciência do Direito vai além do legalismo estrito de seus enunciados normativos, sua validade deve encontrar respaldo no sistema de valores fundamentais reconhecidos pela sociedade em determinado momento histórico, formando um conjunto de fontes jurídicas a serem adotadas e respeitadas: "o neoconstitucionalismo acentua o novo caráter adquirido na atualidade pela teoria (...) têm proporcionado uma cobertura justeórica conceitual e/ou normativa à constitucionalização do Direito em termos normalmente não-positivistas. (...) distingue-se da abordagem positivista do Direito (...) eminentemente descritiva e preocupada em identificar de modo avalorativo (ou normativamente inerte) o que é o Direito." 10

O pós-positivismo, extraído das bases desse constitucionalismo moderno, não corresponde a uma teoria idealista, edificado sobre concepções metafísicas e abstratas de busca pela moralidade. Em síntese, a teoria jurídica do pós-positivismo constitui um novo modelo de pensamento que tenta aproximar o direito da perspectiva moral e política, quando da resolução de conflitos sociais,

$9{ }^{9}$ Corroborando com a problemática de redução do Direito e da Justiça à lei, Paulo Magalhães da Costa Coelho (2008, p. 223) assim se pronuncia: "Situações existem - e não são raras assim - em que determinada norma jurídica, produzida formalmente dentro dos cânones da Ciência Jurídica, que consagrará tamanha iniquidade e injustiça, negando, por exemplo ao homem, o direito a uma existência digna não só no plano material, como ainda, no ético".

1010 SILVA, Alexandre Garrido da. Pós-positivismo e democracia: em defesa de um neoconstitucionalismo aberto ao pluralismo. In XV Congresso Nacional do CONPEDI/UEA - Manaus. Disponível em: <www.conpedi. org.br>. Acesso em: 01 ago. 2018, p. 3346. 
sem que haja um abandono do sistema normativo. Sua trilha argumentativa é delineada sobre a conjectura de que a teoria do Direito deve experimentar maior conexão conceitual com elementos dotados de conteúdos morais, efetivando valores de humanidade, justiça, equidade, razoabilidade, legitimidade, todos constitucionalmente estabelecidos ${ }^{11}$.

A dogmática moderna oriunda do pós-positivismo reconhece o pluralismo e a dialética como características inerentes ao sistema jurídico, reaproximando o Direito da filosofia, em especial no que se refere tanto a uma maior incorporação constitucional de princípios inspirados na dignidade da pessoa humana, como na releitura aplicada a esses mesmos princípios.

Essa alteração de paradigma oriunda do pós-positivismo começa a conquistar espaço no cenário jurídico atual, possibilitando aos princípios constitucionais alcançarem uma nova dimensão de importância. Começam a ganhar força própria como regras jurídicas, alcançando um novo status, centralizado no reconhecimento da sua carga valorativa, evidenciados pela sua função normativa.

Para a moderna hermenêutica constitucional, os princípios deixam de ser vistos apenas pelo prisma abstrato, valores de incidência limitada, dando espaço a teorias que defendem o Direito como um sistema aberto, possibilitando a aplicação de comandos princípiológicos de forma direta e imediata.

Essa normatividade concedida aos princípios constitucionais, acompanhada da permeabilidade da Constituição a dispositivos externos aos enunciados positivados, representa um novo momento do direito constitucional brasileiro, mais adequado à consecução dos ideais de direitos fundamentais e justiça social, afastando-se das vicissitudes da inflexibilidade que a ciência do Direito assumia em um modelo de positivismo legalista.

O pensamento pós-positivista busca ir além do mero ato de subsunção da norma ao fato (método positivista), evitando limitações generalizadas em que a solução de problemas jurídicos ocorria apenas como base nos textos normativos positivados. Uma teoria capaz de acarretar em resultados socialmente indesejados, em especial quando da análise de hard cases. Esses, principalmente, não podem ser resolvidos por aplicações mecanicistas da lei, cabendo ao jurista adotar um processo hermenêutico norteado pelas demais fontes do direito, em especial os princípios constitucionais que regem seu sistema legal.

Não se quer, com isso, afirmar que os modelos jurídico-positivistas tenham sido estruturados com uma absoluta separação entre direito e moral. Esse, certamente, não é o caso. Todavia, o que o pós-positivismo argumenta é que uma coisa é o reconhecimento da moral como elemento existencial, outra coisa é o conteúdo concedido ao seu núcleo, ou seja, a depender do modelo jurídico em questão, a moral experimentará uma variação de relevância quando do embate com normas jurídico-positivadas.

$11^{11}$ Rafael Marcílio Xerez (2014, p. 129) explica: "A compreensão da constituição como fundamento de validade das demais normas integrantes do ordenamento jurídico, não apenas sob um aspecto formal, mas também sob uma dimensão material, a qual abrange a aferição da compatibilidade das normas infraconstitucionais com os valores protegidos em âmbito constitucional, revela-se, portanto, incompatível com as teorias jusnaturalista e juspositivista. Esta concepção demanda a criação de uma terceira via teórica acerca do fundamento do direito, a qual vem sendo denominada, genericamente, de neopositivismo". 
Como crítica maior ao conceito complexo do pensamento pós-positivista, a doutrina cientifica juspositivista apresenta o fato de se tratar de uma teoria capaz de aumentar o grau de indeterminação da ciência do Direito. Sob a justificativa de aproximar o direito da ética, seria permitido aos operadores um perigoso desapego de conteúdos mínimos do positivismo, mitigando a objetividade do Direito e dando espaço para decisões judiciais fundamentadas ${ }^{12}$ em interpretações ético-jurídica pessoais. Uma imperfeição que não ocorreria no cenário de neutralidade presente no positivismo jurídico, motivo o qual "o positivista entende que o magistrado aplicador do direito conforme suas convicções pessoais compromete a segurança jurídica, argumentando que juízes com posições diferentes poderiam decidir de forma distinta casos similares. Que ao judiciário não seria atribuída legitimidade de criar um novo direito, ainda que 'melhor' e mais conexo à realidade social". (DAURTE; MARQUES, 2014, p.3596).

Como segundo argumento apresentado pelos juspositivistas contra as bases teóricas do pós-positivismo, questiona-se o fato de se tratar de um modelo capaz de afetar o próprio Estado de Direito, por ofender a separação de poderes do Estado, acarretando em uma ingerência indevida do Poder Judiciário. Alega-se que na busca por uma máxima efetividade de princípios constitucionais, seria permitido que juízes realizem julgamentos pautados em convicções pessoais, substituindo, de maneira ilegítima, o Poder Legislativo ${ }^{13}$.

Argumentos válidos, mas, até certo ponto, já refutados, pelo fato de que já não mais se questiona que a presença de certo grau de imprecisão na ciência do Direito não é capaz de retirar seu status de ciência, reconhecendo-se que não se trata de uma ciência exata e sim dialética, sendo dominado por incertezas, em especial frente aos distintos métodos de interpretação a serem adotados, bem como pelo fato de nosso sistema relativizar, em inúmeras situações, a teoria da separação de poderes.

Nesse desiderato, a concepção do fenótipo pós-positivista da ciência jurídica se distancia da matriz juspositivista tanto pela sua natureza teórica (doutrina ética do direito), como pela forma com que incidirá nas relações sociais, solucionando situações concretas pautadas em fundamentos ético-jurídicos, delineando uma ordem principiológica com aptidão para acarretar em direitos e obrigações que não estejam estritamente positivados no sistema normativo, mas que necessitam de plena efetivação pelo Estado e até mesmo por particulares.

Chamamos essa nova concepção de pós-positivismo relutante porque - apesar dos inúmeros avanços quanto ao reconhecimento de teorias destinadas a superar as amarras do espírito positivista em busca de um efetivo alcance dos valores supremos consagrados pela Constituição -

$12^{12}$ Afinal, conforme estabelece Max Moller (2011, p.37): “a constituição tem força vinculante quando suas normas são diretamente aplicadas; (...) A aplicabilidade direta das normas constitucionais constitui um passo adiante em relação ao controle de constitucionalidade. A partir dessa qualidade, é possível utilizar a norma constitucional não apenas para orientar e limitar o conteúdo das leis, mas também para fundamentar pretensões diretamente em uma norma constitucional."

$13^{13}$ Nesse sentido, adequado adicionar que para Noberto Bobbio (1995, p. 226): “A afirmação do dever absoluto de obedecer à lei encontra sua explicação histórica no fato de que, com a formação do Estado moderno, não só a lei se tornou a fonte única do direito, mas o direito estatal-legislativo se tornou o único ordenamento normativo, o único sistema de regulamentação do comportamento do homem em sociedade; e, como a valoração de um comportamento se funda numa norma, podemos acrescentar: o direito estatal-legislativo se tornou o critério único e exclusivo para a valoração do comportamento social do homem". 
ainda percebe-se elevado grau de receio (e mesmo rejeição ${ }^{14}$ ) por parte dos operadores do direito em libertar-se do paradigma jusfilosófico do normativismo em sua vertente tradicional, evadindose de teses que advogam pelo reconhecimento do direito como sistema aberto e a sua adequação as necessidades sociais, sempre sob a mesma justificativa de segurança jurídica e preservação da separação de poderes.

O boom doutrinário do pós-positivismo, oriundo de um berço que remete-se ao período pós-guerra, foi acompanhado do desenvolvimento vertiginoso de pesquisas inéditas nos variados campos do direito. Todavia, ao contrário do que se acreditava inicialmente, esse fato não acarretou no seu amplo reconhecimento jurisprudencial, ainda existindo relutância significativa em relação a fundamentação das lides com base em princípios, costumes ou valores integrantes do paradigma do pós-positivismo constitucional. Esses são constantemente superados por uma aplicação mecanicista da norma positivada, independentemente de quão inadequada ou injusta tais normas aparentem $\operatorname{ser}^{15}$.

Humberto Theodoro Júnior $(2007$, p.12) reconhece que as normas de um sistema jurídico representam parâmetros a serem seguidos por um intérprete, construindo assim um núcleo de certeza que trará certo grau de previsibilidade para as relações sociais. Todavia, também defende que cabe ao aplicador do Direito a adequação da norma jurídica ao momento histórico e social a qual está sendo aplicada. Também é o entendimento de Ivan Lira de Carvalho (1993, p.53), enfatizando que o "texto frio e latente, espelha tão só o instante da sua confecção ou do seu incorporamento ao conjunto normativo. Cabe ao interprete vivificá-la e dar-lhe a destinação adequada às exigências sócio-culturais".

Nesse sentido, não é contraditório ou mesmo paradoxal reconhecer que, mesmo se existisse uma adequada regulação normativa, considerando a capacidade metamórfica e dinâmica da sociedade, esta última sempre estará um passo a frente da realidade normativa positivada ${ }^{16}$, o que demonstra ser essencial evitar equívocos de restrição da ciência do Direito apenas ao campo jurídico da norma estatal. A adequação do Direito a atualidade social necessita de ideologias positivistas e naturalistas, e a única teoria que conseguiu, eficazmente, conciliar harmonicamente importantes elementos integrantes de ambas as escolas, corresponde ao paradigma constitucional do pós-positivismo jurídico.

\section{GRADUALISMO REGULADOR E OS AVANÇOS E RETROCESSOS NO PROCESSO DE NORMATIZAÇÃO DO DIREITO DO TRABALHO}

É irrefutável o argumento de que a própria Constituição brasileira foi a maior responsável em estabelecer a obrigatoriedade de um modelo de mercado que fomente a cooperação entre capital

\footnotetext{
$14{ }^{14}$ A título de exemplo, pode-se apontar o texto do jurista catalão Albert Calsamiglia, que apresenta severas críticas a teoria do pos-positivismo em seu artigo "Postpositivismo", disponível em: http://www.lluisvives.com/servlet/ SirveObras/doxa/23582844322570740087891/cuaderno21/voli/Doxa21 12.pdf, acesso em 15/07/2018.

$15^{15}$ Tratam-se, conforme a doutrina de Noberto Bobbio, das chamadas lacunas ideológicas.

$16{ }^{16}$ Conforme advertiu o jurista francês Geroges Ripert: "Quando o Direito ignora a realidade, a realidade se vinga, ignorando o Direito".
} 
e trabalho ${ }^{17}$. Trata-se de um objetivo harmonioso e que apenas pode ser alcançado por meio de um sistema intervencionista, portador de um elevado grau de regulação a incidir tanto sobre o setor econômico como sobre as relações de trabalho, pois, conforme nos lembra Charles Handy (1999, p. 131): "Se deixadas por si, as coisas não funcionam necessariamente para melhor. O laissez-faire é desprovido de valor. Ninguém é responsável por ninguém. Isso é egoísmo inadequado e pode ser autodestrutivo. Precisamos de algo melhor. O capitalismo, como ideia, inclui o capital social bem como o capital econômico. Um deles, sem o outro, não vai funcionar por muito tempo.”

Nesse ponto, cabe um adendo. Obviamente que esse processo regulatório não pode ser encarado com leviandade, não devendo ser confundido com a simplicidade de produção de um número maior de leis. As heranças históricas de nosso sistema jurídico já nos transforma em uma nação portadora de elevado grau de regulação. Essa enxurrada normativa não necessariamente significou uma melhor tutela estatal dos direitos fundamentais.

Esse exagero de leis traz elevada dificuldade de acompanhamento quando de suas mudanças. Regras anacrônicas, múltiplas antinomias, continuam a se proliferar, amontoandose a outras normas esvaziadas de qualquer eficácia social. O desdobramento desse problema de "empilhamento normativo" não é apenas teórico. Afinal, em um cenário onde os próprios especialistas do direito experimentam grande dificuldade para compreender as leis, o que se pode esperar do cidadão comum?

Todavia, o necessário aperfeiçoamento da função legislativa é um problema que não é monopolizado pelo Brasil e certamente desvia de nosso objeto central de reflexão ${ }^{18}$.

O processo de "gradualismo regulador", ora defendido, deverá aflorar pautado em uma maior acuidade perante a complexidade da questão enfrentada, necessitando serem forjadas de forma harmônica aos ideais pós-positivistas, reconhecendo o dinamismo da sociedade contemporânea bem como festejando o Direito como um sistema aberto" ${ }^{19}$, seguindo "uma nova tendência legislativa, em que a preocupação maior é com a harmonia das relações." (CALMON,

$17^{17}$ Art. 170, CF/88: “A ordem econômica, fundada na valorização do trabalho humano e na livre iniciativa, tem por fim assegurar a todos a existência digna, conforme os ditames da justiça social (...)”.

$18^{18}$ Para Eliana Calmon (2001, p. 45) a lógica da alocação de princípios ao Direito, e o abandono desses da mera função simbólica para uma função efetiva, trata-se de uma alteração do epicentro do Sistema Jurídico, resultado da compreensão de que a lógica de redução do direito a norma positivada havia deixado desguarnecido de proteção distintos conflitos, em especial aqueles oriundos de uma "nova onda de demandas" oriundos da "velocidade da vida". Para a autora "as normas jurídicas vem perdendo, gradativamente, a capacidade de ordenar e moldar a sociedade. (...) O fenômeno atinge a todos, sejam países da common law, que adotam para o Judiciário o sistema de precedentes, como também nações que, como o Brasil, pautam-se no sistema da legalidade ou da segurança jurídica, a civil law." $19^{19} \mathrm{Em}$ sentido similar, porém apresentando uma problemática distinta, merece destaque a tese "regulatory renaissance" de PIORE e SCHANK (2008). O argumento dos autores é dividido em duas partes. A segunda, a qual nos filiamos, entende que um dos problemas experimentados a título de efetividade da normatização trabalhista em países da América Latina se refere não apenas ao teor da norma, mas principalmente, à fiscalização do Estado. Para os autores, o cenário experimentado por esses países é o de um Estado "incompetente ou até mesmo corrupto". Argumentam que pouco adiantaria o desenvolvimento de normas regulatórias do trabalho em uma atmosfera em que a fiscalização trabalhista atua de forma inadequada. Realçando a aplicação desse argumento ao cenário Brasileiro, merece destaque o fato de que no ano de 2014, conforme dados do SINAIT (Sindicato Nacional dos Auditores do Trabalho), o Brasil experimentava um contingente de apenas 2.741 Auditores-Fiscais do Trabalho. Um número longe do ideal frente ao exponencial crescimento econômico do país. Inclusive, no ano de 2012, dados do IPEA demonstravam a necessidade de um aumento mínimo de 5.800 auditores para que eles conseguissem, de forma adequada, assegurar o cumprimento da normatização trabalhista. Essa insuficiência no número de AFT fez com que o SINAIT, no dia 19/05/2014, apresentasse denúncia oficial na OIT contra o governo brasileiro pelo descumprimento da Convenção $\mathrm{N}^{\mathrm{o}} 81$, art. 10, da OIT, que prevê que "o número de inspetores do trabalho será o suficiente para garantir o desempenho efetivo das funções do serviço de inspeção (...)”. 
2001, p. 47).

A realidade é que não deveriam existir dúvidas quanto ao fato de que o ordenamento brasileiro em vigor adotou fortes traços de um modelo de institucionalismo, em que se repassou ao Estado a responsabilidade de limitar a autonomia individual dos membros da sociedade ${ }^{20}$. No entanto, também torna-se evidente que esse grau de intervencionismo estatal na regulação de trabalho tem, desde 1964 (substituição da estabilidade decenal pelo regime do FGTS ${ }^{21}$ ), experimentado distintas regressões sociais, permitindo a inserção de elementos caracterizadores em modelos eminentemente contratualistas, marcados pela prevalência da livre vontade intrapartes, ou seja, da autoridade empresarial e do trabalhador.

Isso significa que, no âmbito do sistema de relações de trabalho pátrio, pode ser identificado a influência das matrizes do capitalismo de livre mercado, com a existência de uma ruptura com o modelo institucionalista "puro", convergindo-se para a adoção de um "sistema híbrido", dotado de muitos dos parâmetros característicos em ordenamentos contratualistas, permitindo maiores níveis de discricionariedade empresarial. Essa "ruptura institucional promovida em abril de 1964, além de lançar o Brasil num contínuo processo de concentração de poder, marca a ampliação da internacionalização da economia brasileira e sua definitiva inserção numa sociedade de consumo de massas" (MENDES, 2007. p. 52).

O grande problema oriundo da adoção desse modelo repousa na existência de uma notória inter-relação entre concentração de capital e poder com insegurança e precarização social. $\mathrm{O}$ avanço de um é, comumente, acompanhado pelo cerceamento do outro, mesmo que, em muitas das vezes, esse processo seja menos evidente, ocorrendo de modo não linear.

Desmistificando qualquer ilusão que desconhece a correlação entre retirada/concentração, estabilidade/instabilidade, em um sistema de acúmulo de capital, James Petras (1996, p.126) argumenta que há uma perspectiva global de competição capitalista decisivo para a manutenção do sistema, qual seja, o fato de que "as mudanças dos direitos trabalhistas e sociais, assim, estão incorporadas em um discurso centrado na produtividade e competitividade. Esta abordagem assume a primazia dos interesses capitalistas". Continuando seu raciocínio, PETRAS (1996, p. 126) assinala que "No intuito de se tornarem mais competitivas, como exigência do mercado, as empresas procuram reduzir os custos da produção, por diversos meios, dentre os quais o rebaixamento dos salários, a extinção de vantagens obtidas pelos trabalhadores e de postos de trabalho, sem perspectivas de recuperação

Conforme alertado, sob a justificativa de aumento dos direitos de liberdade empresarial, desde a década de 1960 a organização do trabalho, no Brasil, vêm direcionando-se a adoção de um modelo de espírito contratualista, retirando-se, gradualmente, garantias institucionais estabelecido

\footnotetext{
$20^{20}$ Essa necessidade regulação social pelo Estado demonstra-se necessário pelo evidencia de que o crescimento econômico sem parâmetros ou limites não significará o progresso social de uma nação. Antônio Rodrigues de Freitas Júnior (2011, p.21) nós lembra que "Não quer dizer que um ambiente econômico favorecido traga como subproduto, invariavelmente, expansão de direitos sociais, redução da desigualdade, nem mesmo automático alívio da pobreza. Vimos, por exemplo, como o crescimento econômico do primeiro período da Revolução Industrial trouxe poucos benefícios sociais e muita pobreza absoluta."

$21^{21}$ A criação do FGTS ocorreu por meio da Lei 5.107/66, responsável em iniciar o processo de supressão da estabilidade decenal estabelecida pelo artigo 492 da CLT.
} 
nas relações de trabalho, ao mesmo tempo que são desenvolvidas novas espécies de contratos laborais, esses, dotados de uma natureza mais flexível para "supostamente" melhor se adequarem a modernidade 22 .

Em estudo específico acerca da flexibilização normativa dos institutos do Direito do Trabalho ocorrido nos governos de Fernando Henrique Cardoso (FHC) e Luiz Inácio da Silva (Lula), Grijalbo Fernandes Coutinho (2009, p.73) identifica inúmeras políticas neoliberais que acarretaram na precarização das relações de trabalho. Para o pesquisador, no governo de FHC, pode-se identificar: contrato a tempo parcial (que, ferindo as máximas de isonomia, reduziria direitos trabalhistas como aviso prévio, FGTS e contribuições sociais), banco de horas (lei 9.601/98 passou a possibilitar a compensação de horas extraordinárias, desde que dentro do limite de cento e vinte dias; A MP 2.164-41 de 2001 continuaria o processo flexibilizante, aumentando o prazo de compensação para um ano), Não remuneração de até dez minutos diários de sobrejornada (MP 2.164-41, indo de encontro a expressa previsão constitucional que estabelece a obrigatoriedade de remuneração do trabalho extraordinário, independentemente de sua quantidade), Retirada da natureza salarial de inúmeras verbas trabalhistas historicamente reconhecidas como salário (Lei 10.243/2001), Suspensão do contrato de trabalho para qualificação profissional (MP 2.164-41, para o autor verdadeiro retrocesso por contrariar "a lógica do interesse, por parte do empregador, em prestar os melhores serviços aos seus clientes, arcando com o ônus respectivo."), entre outras formas de flexibilização.

Adentrando o governo Lula, Grijalbo Fernandes Coutinho (2009, p.117) aponta: redução de direito dos trabalhadores pela Lei de Falência (Lei n. 11.101/2005, aprovado sobre "uma propaganda enganosa no sentido de que é melhor o empregado perder um pouco do seu crédito a colocar em risco o posto de trabalho. No final do processo, bem sabemos que a maior parte dos trabalhadores não consegue manter o emprego, além de ter o seu crédito reduzido."), "desreconhecimento" do vínculo empregatício entre motorista de transporte de carga e empresa do setor (Lei n. 11.142/2007), autorização para contratação de trabalhadores rurais sem anotação na CTPS (MP n. 410 de 2007), concessão de crédito bancário mediante desconto na folha de pagamento do empregado (MP 10.820 de 2003, estabeleceu o chamado "crédito consignado" que contribuiria para o endividamento de muitos trabalhadores brasileiros. Para o autor, os benefícios dessa modalidade de flexibilização não foram colhidas pelo empregador, e sim pelos bancos "que passaram a ter uma clientela até então fora de seu alcance comercial direto, com garantia do recebimento de tais empréstimos mediante taxas de juros exorbitantes") (COUTINHO, 2009, p.142), autorização para redução do intervalo intrajornada via negociação coletiva (Portaria n. 42 de 2007), apenas para citar algumas das medidas precarizantes.

Os exemplos acima evidenciam que o ideário neocontratualista tem experimentado certo grau de sucesso em estimular a disseminação de sua doutrina sobre os institutos do Direito do Trabalho brasileiro, ao mesmo tempo em que busca a substituição da intervenção do Estado pela $22^{22}$ Defende-se uma ilusão de cooperação voluntária, estruturada na autonomia contratual das partes e na capacidade delas de produzirem maiores vantagens a cada um. Porém conforme nos lembra Timothy J. Gorringe (1997, p.61), sem a intervenção do Estado, não há uma divisão de benefício já que "a ideia de cooperação voluntária sempre foi uma ficção, pois os fortes tem os fracos à sua mercê". 
autonomia privada. Trata-se de uma afirmação que pode ter toda sua gênese história traçada com precisão (conforme relatado nos parágrafos anteriores) e que invariavelmente resultou em um modelo de Reforma Trabalhista, no ano de 2017, incapaz de surpreender estudiosos do direito trabalhista que já chamavam a atenção para esse problema de expansão de ideários ultraliberais no ramo científico do Direito do Trabalho.

\section{CONSIDERAÇÕES FINAIS}

Foi mediante a apresentação de uma premissa ludibriadora, centralizada no mito de que o fortalecimento que os sindicatos experimentaram nas últimas décadas, alcançando maiores níveis de organização e comprometimento, seriam o suficiente para superar a assimetria existente entre a relação capital e trabalho, que se justificou a necessidade de uma gradual diminuição do dirigismo estatal, deixando espaço para que os próprios interlocutores sociais definissem, mediante negociação, as regram que comporão as relações de trabalho, adequando-as as realidades de cada contexto laboral ${ }^{23}$.

O argumento apresentado por essa corrente ultraliberal, para justificar a retirada da tutela estatal e o fortalecimento da autonomia contratual das partes, se trata de uma hipótese não evidenciada pela realidade brasileira.

É verdade que a estrutura sindical nacional tem experimentado avanços positivos nos últimos anos. Todavia, isso não significa que os sindicatos já detêm uma força e autonomia capaz de fazer frente com a classe empresarial que lhe opõe. Ainda há muito a se conquistar até que as entidades sindicais consigam demonstrar que o Estado pode passar a ocupar um papel coadjuvante no âmbito da regulação laboral ${ }^{24}$. Não se trata de desvalorizar o direito coletivo do trabalho, nem mesmo de menosprezar a importância do diálogo social entre os atores envolvidos no mundo do trabalho, e sim de uma conscientização que, facilmente, pode ser comprovada, para isso basta observamos o incremento de cláusulas em instrumentos coletivos destinados não ao progresso, e sim a regressividade social, mitigando direitos e garantias essenciais, anteriormente alcançados.

O modelo de sindicalismo atual ainda não se encontra preparado para assumir o palco principal da atividade tutelar dos direitos e garantias dos trabalhadores, que seria a realidade que justificaria a mudança de perspectiva mediante o início de um processo de diminuição do

$23{ }^{23}$ Segundo Gustavo Filipe Barbosa Garcia (2013, p.52): "Salienta-se que o tempo necessário para qualquer mudança na legislação trabalhista, como de um dispositivo da CLT, torna praticamente impossível atender às necessidades e urgências inerentes ao mundo do trabalho atual, cuja dinâmica, além de superar as previsões que são feitas, é mais célere do que os atuais processos legislativos, normalmente formais e burocráticos. Como se não bastasse, as entidades sindicais, por meio de procedimentos mais rápidos e informais, de natureza negociada, estariam mais aptas a criar e adaptar as normas específicas para cada circunstância e setor da econômica, por meio da negociação coletiva de trabalho, procedimento democrático que disciplina as relações de trabalho e pacifica os conflitos trabalhistas."

$24{ }^{24}$ Reitera-se que reconhecemos a complexidade inerente a essa questão, bem como a problemática central desse argumento, qual seja, a manutenção do status quo, pois, ao se entender pelo despreparo das entidades sindicais contemporâneas, pode-se justificar a perpetuação do modelo corporativista em vigor entendendo, como adequado, o elevado grau de intervencionismo do Estado nós órgãos sindicais, impedindo que se possa alcançar a tão almejada liberdade sindical. Portanto, entre essas duas perspectivas polarizadas, manifesta-se um verdadeiro "dilema de Antígona", questionando-se se melhor seria conceder um grau maior de liberdade para as entidades sindicais adequarem direitos e obrigações nas relações de trabalho ou, considerando o despreparo dessas entidades, mais seguro para a manutenção de direitos históricos dos trabalhadores, seria um maior preenchimento das fontes jurídicas por meio do Estado? 
grau de intervencionismo do Estado acompanhado de proporcional fortalecimento de um modelo contratualista.

\section{Pelo contrário.}

Nesse atual contexto, a melhor saída para a realidade experimentada pelo Direito do Trabalho brasileiro, seria um retorno das teorias centralizadas em uma maior participação do Estado na regulação das relações laborais, resgatando a ideia de limitação das cláusulas contratuais em matéria de direitos sociais básicos, onde essas não mais prevaleceram sobre as normas oriundas do Estado quando estabelecer condições inferiores aos direitos sociais historicamente conquistados, não se podendo tolerar a retirada de direitos de trabalhadores sob a simples justificativa de necessidade de modernização empresarial que permitiriam uma maior competitividade da empresa brasileira em um mundo globalizado ${ }^{25}$.

\section{REFERÊNCIAS BIBLIOGRÁFICAS}

BARCELLOS, Ana Paula de. Neoconstitucionalismo, direitos fundamentais e controle das políticas públicas. SARMENTO, Daniel; GALDINO, Flávio (orgs.). Direitos Fundamentais: estudos em homenagem ao professor Ricardo Lobo Torres. Renovar: Rio de Janeiro, 2006.

BARROS, Celso. O direito como razão e como história. Doutrinas Essenciais de Direito Civil. São Paulo, v. 1, out/2010.

BARROSO, Luís Roberto. Fundamentos Teóricos e Filosóficos do Novo Direito Constitucional Brasileiro. in Revista Diálogo Jurídico. ano I, vol. 1, Salvador, set/2001. Disponível em <http:// www.direitopublico.com.br/pdf_6/dialogo-juridico-06-setembro-2001-luis-roberto-barroso.pdf $>$. Acesso em: 01/03/2019.

BOBBIO, Noberto. O Positivismo Jurídico: Lições de Filosofia do Direito. São Paulo: Ícone, 1995.

Noberto. Teoria do Ordenamento Jurídico. 6. ed. São Paulo: Editora Universidade de Brasília, 1995.

\section{CALMON, Eliana. As Gerações dos Direitos e as Novas Tendências. Revista de Direito do}

Consumidor. São Paulo, n. 39, jul./set. 2001.

CARVALHO, Ivan Lira. A Interpretação da Norma Jurídica (Constitucional e Infraconstitucional). Revista dos Tribunais. São Paulo, v. 83, n. 693, p. 50-58, jul. 1993.

COELHO, Paulo Magalhães da Costa. A Ciência do Direito: Uma Ciência sem Valores? Revista

$25^{25}$ Coadunando com esse posicionamento Dinaura Godinho Pimento Gomes (2007, p.20), que ao refletir acerca da dispensa da tutela de intervenção do Estado nas relações justrabalhistas, aponta que: "Inegavelmente, tais exigências colidem com os princípios fundamentais a reger o Estado Democrático de Direito, eis que, sob sua égide, acima dos interesses voltados a aumentar a eficiência produtiva, mantendo-se o alto nível de competitividade, está a dignidade do trabalhador. Assim e bem ao contrário do que propugnam esses ideólogos do neoliberalismo, ao Estado cumpre cada vez mais intervir nas relações jurídicas, para garantir a realização dos direitos fundamentais de cada cidadão, principalmente através do trabalho, enquanto meio preponderante de assegurar o direito à vida com dignidade". Para KAUFMANN (2006), torna-se absolutamente necessário a busca por propostas de reformulação da dogmática do Direito do Trabalho, recuperando a natureza expansionista dessa ciência jurídica, dotando-a de ferramentas normativas adequadas para a tutela do homem que encontra-se inserido nesse mar de flexíveis formas de prestação da mão de obra. 
do Instituto dos Advogados de São Paulo. São Paulo, n. 22, v. 06, , p. 199-230, set/2008.

COUTINHO, Grijalbo Fernandes. O Direito do Trabalho Flexibilizado por FHC e Lula. São Paulo: LTr, 2009.

DUARTE, Hugo Garcez; MARQUES, Leonardo Augusto Marinho. Pós-positivismo e hermenêutica: o novo papel do juiz ante à interdisciplinaridade e a efetiva tutela dos direitos fundamentais. In XV Congresso Nacional do CONPEDI/UEA - Manaus. Disponível em: <www.conpedi.org.br>. Acesso em: 01 ago. 2014.

FREITAS JUNIOR, Antônio Rodrigues. História Universal e Direito do Trabalho. Revista de Direito do Trabalho. São Paulo, v. 144, out/2011.

GARCIA, Gustavo Filipe Barbosa. 70 Anos da Consolidação das Leis do Trabalho e Reforma Trabalhista: O debate sobre a desregulamentação e a flexibilização. In Revista de Direito do Trabalho. São Paulo, v. 150, mar/2013.

GEMIGNANI, Tereza Aparecida Asta. Direitos Fundamentais e sua Aplicação no Mundo do Trabalho - Questões Controversas. São Paulo: LTr, 2010.

GOMES, Ana Virgínia Moreira. A aplicação do princípio protetor no direito do trabalho. São Paulo: LTr, 2001.

GOMES, Dinaura Godinho Pimentel. A constitucionalização do direito do trabalho: interpretação e aplicação das normas trabalhistas para a efetiva inter-relação dos interesse econômicos com o respeito à dignidade da pessoa humana. Revista de Direito Constitucional e Internacional. São Paulo, v. 58, jan/2007.

GORRINGE, Timothy J. O Capital e o Reino: ética teleológica e ordem econômica. São Paulo: Paulus, 1997.

HANDY, Charles. Além do capitalismo. São Paulo: Makron Books, 1999.

KAUFMANN, Marcus de Oliveira. Por uma nova dogmática do direito do trabalho: implosão e perspectivas. In Revista de Direito do Trabalho. São Paulo, v. 121, jan./2006.

MENDES, Marcus Menezes Barberino. Justiça do Trabalho e Mercado de Trabalho: Trajetória e Interação Judiciário e a Regulação do Trabalho no Brasil. Dissertação (Mestrado em Desenvolvimento Econômico) - Universidade Estadual de Campinas. Instituto de Economia. Campinas, 2007.

MOLLER, Max. Teoria Geral do Neoconstitucionalismo: bases teóricas do constitucionalismo contemporâneo. Porto Alegre: Livraria do advogado, 2011. PETRAS, James. Brasil: a Retirada dos Direitos Sociais e Trabalhistas. Revista de Ciências Humanas. Universidade de Santa Catarina. Florianópolis, n. 2, v. 14, jul/dez. 1996.

PIORE, Michael J. SCHRANK, Andrew. Toward Managed Flexibility: The Revival of Labour Inspection in the Latin World. In International Labour Review. Geneva, n. 01, v. 147, jan. 2008. 
SILVA, Alexandre Garrido da. Pós-positivismo e democracia: em defesa de um neoconstitucionalismo aberto ao pluralismo. In XV Congresso Nacional do CONPEDI/UEA Manaus. Disponível em: <www.conpedi.org.br>. Acesso em: 01 ago. 2014.

SOARES FILHO, João Batista. A Crise do Direito do Trabalho - Diagnóstico e Perspectivas de Superação. Revista Científica. São Paulo, n. 1, v. 2, jan./jun. 2007.

THEODORO JÚNIOR, Humberto. Interpretação e Aplicação das Normas Jurídicas. In Revista de Processo. São Paulo, v. 150, ago./2007.

XEREZ, Rafael Marcílio. Concretização dos Direitos Fundamentais: Teoria, Método, Fato e Arte. Rio de Janeiro: Lumen Juris, 2014.

Como citar: ALMEIDA, Saulo Nunes de Carvalho. Contratualismo x institucionalismo: a busca por um caminho para a ciência do direito do trabalho. WTO-OSC/ds267 - Pland Cotton. Scientia Iuris, Londrina, v. 23, n. 2, p. 166-182, jul. 2019. DOI: 10.5433/2178-8189.2019v23n2p166. ISSN: 2178-8189.

Recebido em: 19/04/2019.

Aprovado em: 23/07/2019. 